\title{
Analysis of real-world data on growth hormone therapy adherence using a connected injection device
}

\author{
Ekaterina Koledova $^{1 *}$ D, Vincenzo Tornincasa ${ }^{2}$ and Paula van Dommelen ${ }^{3}$
}

\begin{abstract}
Background: Poor adherence to long-term recombinant human growth hormone ( $r-h G H)$ treatment can lead to suboptimal clinical outcomes; consequently, supporting and monitoring adherence is a crucial part of patient management. We assessed adherence to $\mathrm{r}$-hGH treatment in children with growth disorders over 48 months using a connected monitoring device (easypo $\mathrm{d}^{\mathrm{TM}}$ ), which automatically transmits adherence data via an online portal (easypod $^{\mathrm{TM}}$ connect); both sit within an adherence decision support system (ADSS). We also investigated the effect of age and sex on adherence.
\end{abstract}

Methods: Data from children transmitting over 10 injections between January 2007 and February 2019 were analyzed. Adherence (mg injected/mg prescribed) was categorized as high $(\geq 85 \%)$, intermediate $(>56-84 \%)$ or low $(\leq 56 \%)$ and assessed at seven time points from the start of treatment up to 48 months. Adherence was investigated over time and stratified by puberty status and sex. Mean transmission rate in each adherence category (total number of transmissions/total number of children) at each time point was calculated as a proxy measure of engagement in disease and treatment management. Descriptive analyses were performed.

Results: Longitudinal records were available for 13,553 children. Overall, 71\% ( $n=9578)$ had high adherence, $22 \%$ $(n=2989)$ intermediate and 7\% $(n=986)$ low. The proportion of children with high adherence decreased over time from $87 \%(n=12,964)$ to $65 \%(n=957)$ and was higher in pre-pubertal than pubertal children (girls: $80 \%[n=1270]$ vs $70 \%[n=4496]$; boys $79 \%[n=2573]$ vs $65 \%[n=5214])$. Children with high adherence had a higher mean number of transmissions (12.5 [SD 24.9]) than children with intermediate (7.2 [SD 15.3]) or low (3.5 [SD 5.7]) adherence.

Conclusions: High adherence was seen in patients administering r-hGH using the connected device. Children with high adherence were most likely to regularly transmit data. Pubertal children showed lower adherence. We show the potential to develop an ADSS to analyze trends in real-world adherence data. This may prove useful to direct interventions to improve adherence while the ability to readily share data with healthcare professionals may itself improve adherence.

Keywords: Adherence, eHealth, Electromechanical injection device, Growth disorders, Growth hormone, Population health

\footnotetext{
* Correspondence: ekaterina.koledova@merckgroup.com

${ }^{1}$ Endocrinology Global Medical, Safety and CMO, Merck KGaA, 64293

Darmstadt, Germany

Full list of author information is available at the end of the article
}

(C) The Author(s). 2020 Open Access This article is licensed under a Creative Commons Attribution 4.0 International License, which permits use, sharing, adaptation, distribution and reproduction in any medium or format, as long as you give appropriate credit to the original author(s) and the source, provide a link to the Creative Commons licence, and indicate if changes were made. The images or other third party material in this article are included in the article's Creative Commons licence, unless indicated otherwise in a credit line to the material. If material is not included in the article's Creative Commons licence and your intended use is not permitted by statutory regulation or exceeds the permitted use, you will need to obtain permission directly from the copyright holder. To view a copy of this licence, visit http://creativecommons.org/licenses/by/4.0/ The Creative Commons Public Domain Dedication waiver (http://creativecommons.org/publicdomain/zero/1.0/) applies to the data made available in this article, unless otherwise stated in a credit line to the data. 


\section{Background}

Recombinant human growth hormone ( $\mathrm{r}-\mathrm{hGH}$ ) is used in the treatment of various growth disorders [1]. Suboptimal final growth and poor clinical outcomes [2] can result from poor adherence due to factors such as complex drug regimens, limited access to care and issues in puberty [3, 4].

Traditional approaches to monitoring adherence such as patient testimony, or proxy measurements, such as prescription records or vial counting [5], are not sufficiently objective. New eHealth-based ecosystems with automatic adherence recording and data transmission allow real-time monitoring of adherence. By alerting healthcare professionals (HCPs) to take action if a decrease in adherence is detected, these ecosystems can provide personalized individual-patient or targeted support for groups of patients at risk of low adherence, thereby contributing to positive population-health outcomes $[6,7]$.

Automatic recording and monitoring of adherence is also important in the development of treatment plans. Innovative eHealth solutions and technologies, as part of an adherence decision support system (ADSS), offer the potential to improve health outcomes by seamlessly tracking adherence according to treatment plans and engaging and informing patients and HCPs through patient support programs (PSPs) [8]. ADSS is a form of clinical decision support that provides HCPs, patients and care providers with timely knowledge and person-specific information, to improve health care and outcomes [9]. Many existing technological interventions aim to address non-adherence to medication but not all deliver the full potential of an ADSS [10-13]. For example, by using an ADSS, the sharing of prospective adherence tracking data with HCPs ahead of scheduled clinic visits may enable HCPs to detect both "true" poor responders to $\mathrm{r}$ hGH treatment and those patients whose poor response is due to suboptimal adherence. The use of mobile phone medical applications is common and has been associated with improved adherence and outcomes in areas such as exercise [14, 15].

Applications also exist for growth monitoring, although these lack integration with a connected drugdelivery device that removes the bias associated with self-reported patient outcomes $[16,17]$. The ability of electronic devices and everyday objects to communicate, interact, be remotely controlled and monitored by other devices through internet connectivity is known as the 'internet of things' (IoT) [18-20]. Advancements in IoTbased applications in the healthcare domain has facilitated collection of real-world data from a wide range of connected devices, such as pill dispensers using medication event monitoring [21-23] and pen devices for the treatment of diabetes [24, 25]. However, there are few
IoT-based solutions for the monitoring and understanding of adherence in other endocrine conditions requiring injectable treatments, where adherence monitoring is key to ensuring optimal care. A prime example is the gap in health technology and informatics for growth hormone deficiency, which requires injectable treatment over long periods of time in a mostly pediatric population [26].

The easypod ${ }^{\mathrm{Tw}}$ injection device was developed for patients with growth hormone deficiency, to meet the requirements for a reliable, easily used, convenient injection device with IoT functionality [27]. It is the first IoT-based connected device to electronically record adherence data (completed and missed doses) for patients receiving $\mathrm{r}$-hGH (Saizen ${ }^{\circ}$, Merck KGaA, Darmstadt, Germany) to treat growth disorders. HCPs can access adherence data via the easypod $^{\mathrm{Tw}}$ connect ecosystem [28]. The easypod ${ }^{\text {Tix }}$ connect transmitter can transfer the injection data recorded by the easypod ${ }^{\mathrm{Tm}}$ to a cloud-based platform using a cellular connection. The data are then accessible to HCPS through the dedicated web-based dashboard or to patients from a mobile application (Fig. 1). Based on the adherence data, HCPs can counsel patients and adjust the dosage so the connected device ecosystem meets the full potential of an ADSS.

The connected device is currently approved for use in more than 40 countries [29]. The observational ECOS study has reported on the robust adherence data that has been collected using the online portal. Most patients maintained an adherence rate of $\geq 80 \%$ for $>3$ years, with poor adherence linked to suboptimal clinical outcomes $[28,30]$. Such data on adherence and engagement with the device in a real-world setting have only recently been available.

Our aim was to perform a real-world observational analysis of the connected device ecosystem to gather insights about recorded adherence and engagement to treatment in children with growth disorders, from the start of treatment up to 48 months. We also investigated the effect of age and sex on adherence.

\section{Methods}

Treatment with the connected device and connect platform was conducted according to local practice. The study employed inclusion/exclusion criteria and an approach to treatment and overall care that was representative of the clinical practice for each of the countries enrolled. Prior to their participation in the real-world, observational, retrospective analysis for monitoring $\mathrm{r}$ hGH adherence and outcomes, both parents of the pediatric patients or the adult patients reviewed and voluntarily signed an informed consent form materializing their agreement for data collection, storage and use of 


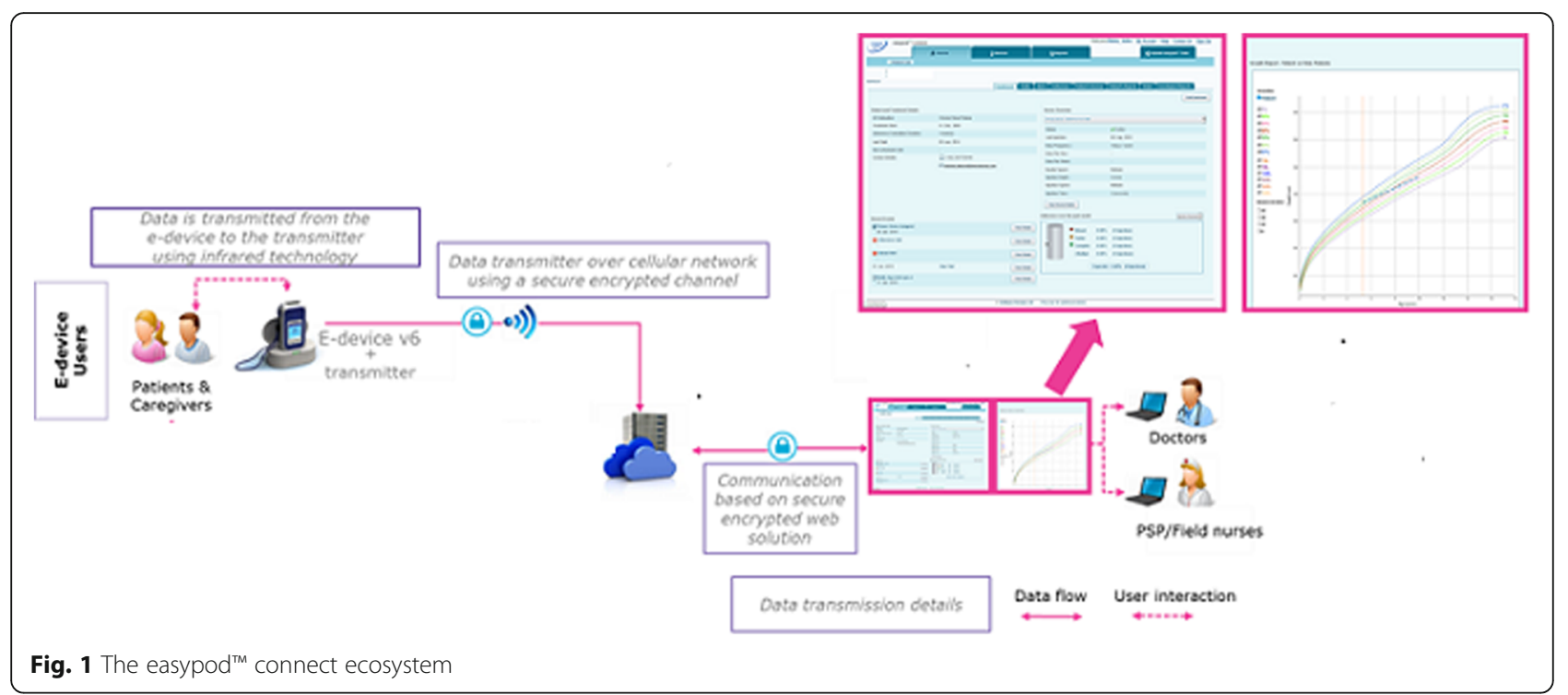

their pseudonymized data to create aggregated statistical and general adherence reports.

\section{Data transmitted to an internet cloud}

The connected device sits within an ecosystem, through which injection data are transmitted to a secure cloud on the internet via a home station (Fig. 1). This ecosystem was used to collect longitudinal data on $>13,553 \mathrm{pa}$ tients to study adherence patterns over a period of 13 years. Data from children transmitting $>10$ injections between January 2007 and February 2019 were analyzed. For the descriptive statistics at each time point, we included the children who were still on treatment at that moment in time.

\section{Definition and grades of adherence}

Adherence (mg injected/mg prescribed) was categorized as high $(\geq 85 \%)$, intermediate $(>56-84 \%)$ or low $(\leq 56 \%)$ [2] and assessed at seven time points. High adherence was defined as missing no more than one dose a week on average. Adherence was then explored by puberty status (nominal cut-offs at 10 years for girls and 12 years for boys) and sex. Dosage and frequency as per the connected device settings were defined by the HCPs.

Data transmissions were instigated by the child, guardian or by HCPs on behalf of the patient at each clinic visit. Adherence was recorded for children transmitting data at each time point. No imputation was made for missing data or withdrawal. For each adherence cohort, the mean number of transmissions (total number of transmissions in each adherence category versus the total number of children in each adherence category) was calculated as a proxy measure of engagement in disease management.

\section{Statistical analysis}

Descriptive statistics were used to describe differences over time in adherence (low/intermediate/high), by puberty status (pre-pubertal/pubertal) and sex, and overall adherence by transmission ratio.

\section{Results}

Longitudinal records were available for 13,553 children between January 2007 and February 2019. Different adherence patterns arose from the data analysis. Overall, more children had high adherence $(n=9578)$ than intermediate $(n=2989)$ or low $(n=986)$ adherence. The proportion of children with high adherence decreased from $87 \%(n=12,964)$ to $65 \%(\mathrm{n}=957)$ between months 1 and 48; however, at each time point up to month 48 , more children had high adherence than low/intermediate adherence (Fig. 2).

Compared with children in the low/intermediate adherence categories, children with high adherence also had the highest mean number of transmissions (Table 1).

The proportion of children with high adherence overall was slightly higher in girls than in boys $(72 \%[N=$ $5766])$ vs $69 \%$ [ $N=7787]$ ); a similar trend was seen at each time point. The proportion of pre-pubertal girls with high adherence was greater than the proportion of pubertal girls $(80 \%[N=1270]$ vs $70 \%[N=4496])$. Similar results were found in boys $(79 \%[N=2573]$ vs $65 \%$ $[N=5214]$ ) (Fig. 3).

\section{Discussion}

We showed the distribution of adherence by age and sex in a large, real-world setting up to 48 months after the start of treatment and concluded that the majority of children who receive $\mathrm{r}-\mathrm{hGH}$ treatment via the connected device had high adherence. A higher proportion of pre- 


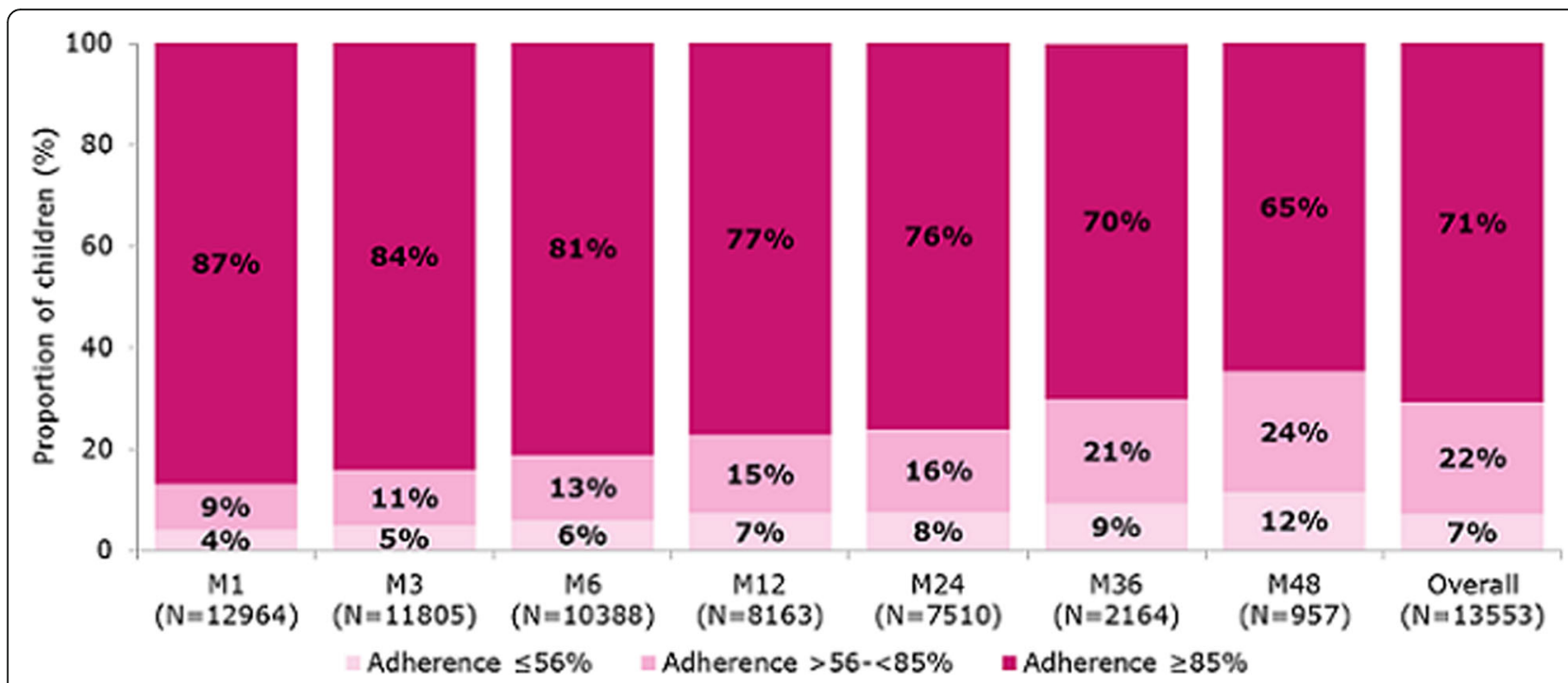

Fig. 2 Proportion of children in each adherence category at each time point. M, month

pubertal than pubertal children and a slightly higher proportion of girls than boys were in the high adherence category. The connected device was a useful tool in this regard as it is unique in providing the most objective measurement of patient adherence to $\mathrm{r}-\mathrm{hGH}$ that is currently available. Monitoring using the connected device is based on the real-time recording of the doses administered compared with those prescribed, rather than incidental or proxy recording methods. Patients using ostensibly objective methods of monitoring can still substantially overestimate their level of adherence to $r-h G H$ treatment, owing to a combination of factors [31].

There was a trend for the children who were most adherent to treatment to be more likely to transmit their injection data results regularly than those who were less adherent. This association between adherence and transmission of data may indicate that sharing data with HCPs impacts adherence rates. The active engagement of patients and caregivers through the use of eHealth solutions is already known to improve treatment adherence in patients with chronic conditions and is associated with long-term improvement in clinical outcomes [31]. Data from wearable and monitoring devices are widely used in observational studies [32, 33]; however, the reporting of adherence data is limited and small scale $[10-13,26]$. This analysis shows the value of large-scale real-world datasets using connected devices, in particular for monitoring hormone treatment adherence.

The results reported here may suggest that pubertal children are at greater risk for suboptimal adherence and may benefit from closer engagement. Real-time monitoring using internet connected devices has the potential to benefit both the patient and the physician and may provide a starting point for discussions on any issues the patient may have encountered. Alternatively, the output can be used proactively on a target group or population level, to identify times or define targets when patients may need particular attention. Integrating a holistic approach to patient care such as patient-reported outcome measures (PROMs) and patient-reported experience measures (PREMs) may improve understanding of non-adherence and inform PSPs [34]. To develop appropriate and succinct PROMs and PREMS, human

Table 1 Overall demographics according to adherence rate

\begin{tabular}{llll}
\hline & $\begin{array}{l}\text { Adherence } \geq 85 \% \\
(n=9578)\end{array}$ & $\begin{array}{l}\text { Adherence }>56 \% \text { to }<85 \% \\
(n=2989)\end{array}$ & $\begin{array}{l}\text { Adherence } \leq 56 \% \\
(n=986)\end{array}$ \\
\hline Boys, mean age (SD) & $12.8(5.3$ years) & $15.0(6.6)$ years & $15.3(7.6)$ years \\
Number of boys $<12$ years/12+ years & $2026 / 3377$ & $417 / 1384$ & $130 / 453$ \\
Girls, mean age (SD) & $12.2(5.2)$ years & $14.3(7.9)$ years & $15.8(10.6)$ years \\
Number of girls $<10$ years/10+ years & $1018 / 3157$ & $195 / 993$ & $57 / 346$ \\
Mean (SD) number of transmissions & $12.5(24.9)$ & $7.2(15.3)$ & $3.5(5.7)$ \\
Mean (SD) global adherence duration, days & $599(530)$ & $694(565)$ & $630(539)$ \\
\hline
\end{tabular}



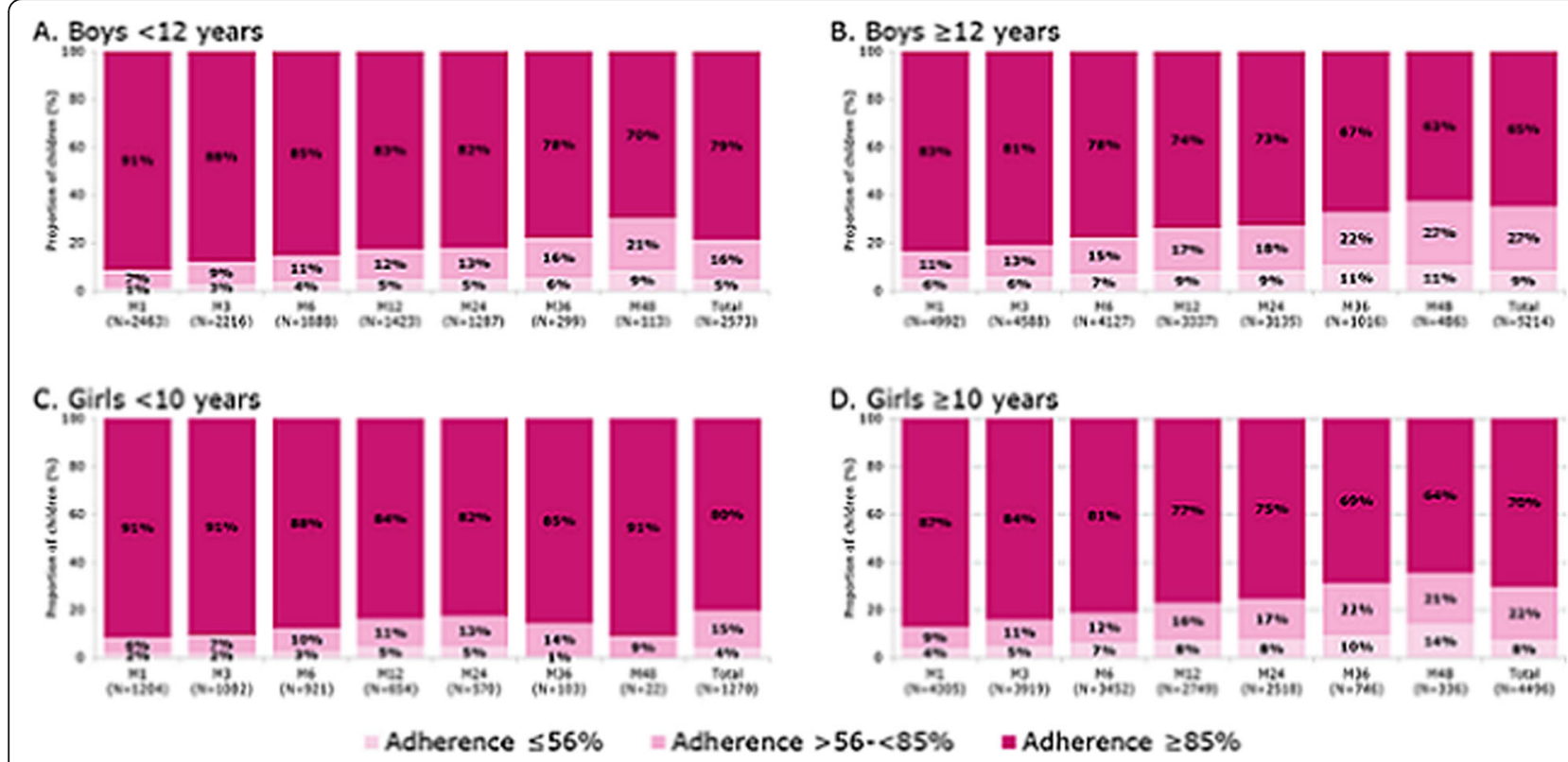

Fig. 3 Proportions of children adherent at each time point according to age and sex. M, month

factor studies on drivers for adherence to hGH would be beneficial [35].

Electronic injection reminders are a feature of the easypod $^{\mathrm{mi}}$ device, however adherence may be further enhanced through mobile phone reminders and applications [36-38]. Gamified interventions for pediatric patients are receiving increasing attention as a potential tool to promote medication adherence through factors such as goal setting, incentive-based engagement and education [38]. Although limited, there is evidence suggesting positive health and behavioral outcomes associated with gamification in pediatric patients [39-41]. Design frameworks are lacking for guiding the development of gamified health interventions and further research is needed within this area to optimize the influence of applications on self-management [42]. To complement the use of the easypod ${ }^{\mathrm{Tx}}$ device, a treatment-support application was recently launched in Hong Kong [43]. It is an educational tool that incorporates elements of gaming to encourage accurate r-hGH administration. The application features an avatar; studies have suggested that use of an avatar can serve as a role model and influence positive behaviors [44]. The impact of this gamified intervention and its potential on a wider scale is yet to be determined.

The advantages of this real-world dataset are the large population base, multinational setting, automated recording of adherence and injection settings and manually entered basic patient characteristics (such as age and sex), and the potential to develop a complete ADSS. The results of this analysis are highly aligned with real-world practice and corroborate individual case studies of children using the connected device, which show that direct monitoring of adherence can affect motivation and management $[6,45,46]$.

However, the dataset has limitations that are inherent in any real-world datasets. For example, there may be missing information (e.g., owing to a lack of transmission) or there may be high inter-patient variability (e.g., owing to changes in the treatment plan or other actions taken by the HCP or child). In addition, many confounding, contextual or patient-specific variables that could influence behavior beyond sex and age are not recorded automatically and therefore were not available for this analysis. Although this study reflects a large amount of data, it should also be considered that data collection practices may differ between countries, which makes such comparisons challenging.

Future opportunities for cross-linking the real-world dataset with electronic medical records (EMRs) or electronic health record (EHR) datasets would make the assessment of outcomes much more insightful, given the greater availability of treatment plans and outcome data now available. Recent developments in computing interfaces focused on supporting seamless data transfer demonstrate potential for approaching integration into EMRs and EHRs [47]. However, direct integration of patient data presents additional challenges such as legal and ethical considerations [48] and the fragmentation of the technological landscape, in which each country appears to have its own specific subset of EHR systems and vendor which are specific to local practice. 


\section{Conclusions}

These results show the potential of using a connected device to study patterns of adherence across large populations. Our real-world data suggest that high adherence is seen in children using the connected device ecosystem for treatment of growth disorders with $\mathrm{r}-\mathrm{hGH}$, although the proportion of children with high adherence decreased over time. More pre-pubertal than pubertal children and slightly more girls than boys had high adherence. Children who were most engaged with the device were more likely to have better adherence. The use of the connected device ecosystem combined with EHRs has the potential to realize an ADSS that can facilitate the assessment of outcomes and adherence plans to support integrated care.

\section{Abbreviations}

ADSS: Adherence decision support system; EHR: Electronic health record; EMR: Electronic medical record; GH: Growth hormone; HCP: Healthcare professional; loT: Internet of things; PREM: Patient-reported experience measure; PROM: Patient-reported outcome measure; PSP: Patient support program; r-hGH: Recombinant human growth hormone

\section{Acknowledgments}

The authors would like to thank Jorge Cancela (previously of Ares Trading, an affiliate of Merck KGaA, Darmstadt, Germany) for designing the analysis, interpreting the data and for providing critical comments. The authors would like to thank Luis Fernandez (Salumedia, Seville, Spain) for his valuable advice and input on digital therapeutics for monitoring adherence in the real world, Merat Bagha (Geneva, Switzerland) for providing critical comments and Ruben Michael Dezeure (Ares Trading, an affiliate of Merck KGaA, Darmstadt, Germany) for performing the statistical analysis. Medical writing assistance was provided by Ella Palmer and Steven Goodrick, inScience Communications, Springer Healthcare Ltd., UK, and sponsored by Merck KGaA, Darmstadt, Germany. The authors would like to acknowledge the children, their families and the healthcare professionals who participated in the analysis.

\section{Authors' contributions}

EK contributed to the planning of the study, data review and interpretation, and writing/revisions/approval of drafts and the final manuscript. VT contributed to the data analysis, review and interpretation, and writing/ revisions/approval of drafts and the final manuscript. PvD contributed to the data review and interpretation, and writing/revisions/approval of drafts and the final manuscript. All authors have read and approved the manuscript.

\section{Funding}

This analysis was funded by Merck KGaA, Darmstadt, Germany. Employees of the funding body are named authors and were, therefore, involved in the design of the study and the collection, analysis and interpretation of the data and in writing and reviewing of the manuscript.

\section{Availability of data and materials}

The datasets generated and/or analyzed during the current study are not publicly available due to the dataset containing information derived from personal data, which could be aggregated to a degree that could potentially identify individual subjects but are available from the corresponding author on reasonable request.

For all new products or new indications approved in both the European Union and the USA after 1 January, 2014, Merck KGaA (Darmstadt, Germany) will share patient- and study-level data after deidentification, as well as redacted study protocols and clinical study reports from clinical trials in patients. These data will be shared with qualified scientific and medical researchers, upon a researcher's request, as necessary for conducting legitimate research. Such requests must be submitted in writing to the company's data sharing portal and will be internally reviewed regarding criteria for researcher qualifications and legitimacy of the research purpose.

\section{Ethics approval and consent to participate}

Treatment with the easypod ${ }^{\mathrm{TM}} /$ easypod ${ }^{\mathrm{TM}}$ connect platform was conducted according to local practice. This real-world, observational, retrospective analysis of the dataset was performed in accordance with the informed consent form, signed by caregivers of children and adult patients materializing their agreement for data collection, storage and use of their pseudonymized data to create aggregated statistical and general adherence reports.

\section{Consent for publication}

Not applicable.

\section{Competing interests}

$\mathrm{VT}$ is an employee of Ares Trading, an affiliate of Merck KGaA, Darmstadt Germany. EK is an employee of Merck KGaA, Darmstadt, Germany. PvD has a consultancy agreement with Merck KGaA, Darmstadt, Germany.

\section{Author details}

${ }^{1}$ Endocrinology Global Medical, Safety and CMO, Merck KGaA, 64293

Darmstadt, Germany. ${ }^{2}$ Merck Connected Health and Devices, Ares Trading S.A., an affiliate of Merck KGaA, 1262 Eysins, Switzerland. ${ }^{3}$ The Netherlands Organization for Applied Scientific Research TNO, Leiden, The Netherlands.

Received: 8 January 2020 Accepted: 10 July 2020

Published online: 29 July 2020

References

1. Richmond E, Rogol AD. Current indications for growth hormone therapy for children and adolescents. Endocr Dev. 2010;18:92-108.

2. Cutfield WS, Derraik JG, Gunn AJ, Reid K, Delany T, Robinson E, Hofman PL. Non-compliance with growth hormone treatment in children is common and impairs linear growth. PLoS One. 2011;6(1):e16223.

3. Hartmann K, Ittner J, Muller-Rossberg E, Schonau E, Stephan R, Ullrich KP, Hoppe B, Ramseger R, Bramswig J. Growth hormone treatment adherence in prepubertal and pubertal children with different growth disorders. Horm Res Paediatr. 2013;80(1):1-5.

4. Rosenfeld R, Bakker B. Compliance and persistence in pediatric and adult patients receiving growth hormone therapy. Endocr Pract. 2008;14(2):14354.

5. Bozzola M, Colle M, Halldin-Stenlid M, Larroque S, Zignani M. Treatment adherence with the easypod growth hormone electronic auto-injector and patient acceptance: survey results from 824 children and their parents. BMC Endocr Disord. 2011;11:4

6. Stoyanov G KE, Vandermeulen J \& the Canadian ECOS Group: Objectively measured treatment adherence in the easypod ${ }^{\mathrm{TM}}$ connect observational study (ECOS). Canadian interim analysis: population data and case reports. In: CPEG. Edmonton, Alberta, Canada: CPEG; 2016.

7. Kindig D, Stoddart G. What is population health? Am J Public Health. 2003; 93(3):380-3.

8. Lee MK, Lee KH, Yoo SH, Park CY. Impact of initial active engagement in self-monitoring with a telemonitoring device on glycemic control among patients with type 2 diabetes. Sci Rep. 2017;7(1):3866

9. Office of the National Coordinator. Clinical Decision Support [https://www. healthit.gov/topic/safety/clinical-decision-support]. Accessed 17 July 2020.

10. Ebner H, Hayn D, Kropf M, Modre-Osprian R, Schreier G. Internet of things based medication adherence assessment. Stud Health Technol Inform. 2016; 221:118.

11. Lakshmi Dhevi B, Vishvaksenan KS, Senthamil Selvan K, Rajalakshmi A. Patient monitoring system using cognitive internet of things. J Med Syst. 2018;42(11):229.

12. Schreier G. The internet of things for personalized health. Stud Health Technol Inform. 2014;200:22-31.

13. Stegerman SBJ, Cerreta F, Chanie E, Leofgren A, Maio M, Schreier G, Thesing-Bleck E. Adherence measurement systems and technology for medications in older patient populations. Eur Geriatr Med. 2012;3:254-60.

14. Althoff T, White RW, Horvitz E. Influence of Pokemon Go on Physical Activity: Study and Implications. J Med Internet Res. 2016;18(12).

15. Ventola CL. Mobile devices and apps for health care professionals: uses and benefits. P T. 2014;39(5):356-64.

16. Althubaiti A. Information bias in health research: definition, pitfalls, and adjustment methods. J Multidiscip Healthc. 2016;9:211-7. 
17. Fernandez-Luque L, Labarta Jl, Palmer E, Koledova E. Content analysis of apps for growth monitoring and growth hormone treatment: systematic search in the android app store. JMIR Mhealth Uhealth. 2020;8(2):e16208.

18. Zanella ABN, Castellani A, Vangelista L, Zorzi M. Internet of things for Smart cities. IEEE Internet Things J. 2014;1:22-32.

19. Al-Shaqi R, Mourshed M, Rezgui Y. Progress in ambient assisted systems for independent living by the elderly. Springerplus. 2016;5:624.

20. Ma LN, Nguyen, H, Mirza, F, Neuland O. Two way architecture netween IOT sensors and cloud computing for remote health care monitoring applications. In: 25th European Conference on Information Systems (ECIS): June 5-10, 2017. Guimarães: Research-in-Progress Papers; 2017. p. 2834-41.

21. Misdrahi D, Tessier A, Husky M, Lange AC, Vrijens B, Llorca PM, Bayle FJ. Evaluation of adherence patterns in schizophrenia using electronic monitoring (MEMS(R)): a six-month post-discharge prospective study. Schizophr Res. 2018;193:114-8.

22. Forbes CA, Deshpande S, Sorio-Vilela F, Kutikova L, Duffy S, Gouni-Berthold I, Hagstrom E. A systematic literature review comparing methods for the measurement of patient persistence and adherence. Curr Med Res Opin 2018;34(9):1613-25.

23. MEMS Cap [https://www.aardexgroup.com/solution/mems-caps/22]. Accessed 17 July 2020

24. Clifford S, Perez-Nieves M, Skalicky AM, Reaney M, Coyne KS. A systematic literature review of methodologies used to assess medication adherence in patients with diabetes. Curr Med Res Opin. 2014;30(6):1071-85.

25. Toussi M, Choleau C, Reach G, Cahane M, Bar-Hen A, Venot A. A novel method for measuring patients' adherence to insulin dosing guidelines: introducing indicators of adherence. BMC Med Inform Decis Mak. 2008;8:55.

26. Diemert S, Weber J, Price M, Bannman J. Data for adherence decision support. Stud Health Technol Inform. 2019;257:75-9.

27. Dahlgren J. Easypod: a new electronic injection device for growth hormone. Expert Rev Med Devices. 2008;5(3):297-304.

28. Koledova E, Stoyanov G, Ovbude L, Davies PSW. Adherence and long-term growth outcomes: results from the easypod connect observational study (ECOS) in paediatric patients with growth disorders. Endocr Connect. 2018; 7(8):914-23.

29. Koledova E, Stoyanov G, Ovbude L, Davies PSW. Adherence and long-term growth outcomes: results from the easypod() connect observational study (ECOS) in paediatric patients with growth disorders. Endocr Connect. 2018; 7(8):914-23.

30. van Dommelen P, Koledova E, Wit JM. Effect of adherence to growth hormone treatment on 0-2 year catch-up growth in children with growth hormone deficiency. PLoS One. 2018;13(10):e0206009.

31. Dawson LA. What factors affect adherence to medicines? Arch Dis Child Educ Pract Ed. 2019;104(1):49-52.

32. Dunn TC, Xu Y, Hayter G, Ajjan RA. Real-world flash glucose monitoring patterns and associations between self-monitoring frequency and glycaemic measures: a European analysis of over 60 million glucose tests. Diabetes Res Clin Pract. 2018;137:37-46.

33. Willetts $M$, Hollowell S, Aslett L, Holmes C, Doherty A. Statistical machine learning of sleep and physical activity phenotypes from sensor data in 96,220 UK biobank participants. Sci Rep. 2018;8(1):7961.

34. Forestier B, Anthoine E, Reguiai Z, Fohrer C, Blanchin M. A systematic review of dimensions evaluating patient experience in chronic illness. Health Qual Life Outcomes. 2019;17(1):19.

35. Benson T. Measure what we want: a taxonomy of short generic personreported outcome and experience measures (PROMs and PREMs). BMJ Open Qual. 2020;9(1).

36. Schwebel FJ, Larimer ME. Using text message reminders in health care services: a narrative literature review. Internet Interv. 2018;13:82-104.

37. Fedele DA, Cushing CC, Fritz A, Amaro CM, Ortega A. Mobile health interventions for improving health outcomes in youth: a meta-analysis. JAMA Pediatr. 2017;171(5):495.

38. Radovick SHE, Kalisvaart A, Koning M, Paridaens K, Boulos MNK. Gamification concepts to promote and maintain therapy adherence in children with growth hormone deficiency. J Multidiscip Sci J. 2018;1(1):71-80.

39. Lu AS, Kharrazi H, Gharghabi F, Thompson D. A systematic review of health videogames on childhood obesity prevention and intervention. Games Health J. 2013;2(3):131-41.

40. DeShazo J, Harris L, Pratt W. Effective intervention or Child's play? A review of video games for diabetes education. Diabe Technol. 2010;12(10):815-22.
41. Bartholomew LK, Gold RS, Parcel GS, Czyzewski DI, Sockrider MM, Fernandez M, Shegog R, Swank P. Watch, discover, think, and act: evaluation of computer-assisted instruction to improve asthma self-management in innercity children. Patient Educ Couns. 2000;39(2-3):269-80.

42. Giunti G. $3 M D$ for chronic conditions, a model for motivational mHealth design: embedded case study. JMIR Serious Games. 2018;6(3):e11631.

43. Merck KGaA: Easypod ${ }^{\oplus}$ AR (Augmented Reality). In., vol. iOS and Android. Hong Kong: https://play.google.com/store/apps/details?id=de.merck. easypodarapp.googleplay\&hl=zh_HK; https://apps.apple.com/hk/app/ easypod-ar/id1480810409?app=itunes\&ign-mpt=uo\%3D4; 2019.

44. Gabarron E, Serrano JA, Wynn R, Armayones M. Avatars using computer/ smartphone mediated communication and social networking in prevention of sexually transmitted diseases among north-Norwegian youngsters. BMC Med Inform Decis Mak. 2012;12:120.

45. A-FC A-EA, Saavedra-Castillo E, Barrientos-Pérez M, Rivero-Escalante $H$, Flores-Caloca O, Calzada León R, Valdez-Morales F, Koledova E, BlancoLópez A. The Easypod Connect Observational Study (ECOS): descriptive analysis of adherence to treatment of growth hormone deficient and small for gestational age naïve to easypod patients in Mexico 2012-2015. Horm Res Paediatr. 2016;86:103.

46. CR NM, Tauber M, López Y. Easypod ${ }^{\mathrm{TM}}$ Connect Observational Study (ECOS) - French Case Histories And Growth Outcomes. Horm Res Paediatr. 2017; 88(Supplement 1):1-830

47. Sayeed R, Gottlieb D, Mandl KD. SMART markers: collecting patientgenerated health data as a standardized property of health information technology. NPJ Digit Med. 2020;3:9.

48. Sittig DF, Singh H. Legal, ethical, and financial dilemmas in electronic health record adoption and use. Pediatrics. 2011;127(4):E1042-7.

\section{Publisher's Note}

Springer Nature remains neutral with regard to jurisdictional claims in published maps and institutional affiliations.

Ready to submit your research? Choose BMC and benefit from:

- fast, convenient online submission

- thorough peer review by experienced researchers in your field

- rapid publication on acceptance

- support for research data, including large and complex data types

- gold Open Access which fosters wider collaboration and increased citations

- maximum visibility for your research: over $100 \mathrm{M}$ website views per year

At $\mathrm{BMC}$, research is always in progress.

Learn more biomedcentral.com/submissions 